\title{
Bioactive substances of plant origin in food - impact on genomics
}

\author{
Arkadiusz OrZECHOWsKI, Piotr OstASZEWSKI*, Michał JANK, \\ Sybilla Jacqueline BERWID
}

Department of Physiological Sciences, Faculty of Veterinary Medicine,

Warsaw Agricultural University, Poland

\begin{abstract}
In the past decade, substantial progress has been made concerning our knowledge of bioactive components in plant foods and their links to health. Human diets of plant origin contain many hundreds of compounds which cannot be considered as nutrients, but appear to play a role in the maintenance of health. These substances are called nutraceuticals. In some cases where the disease process is at least partially understood, elements of protection can be related to a single compound or structurally related group of compounds in the diet. Bioactive components of food which are of special interest include the following groups: polyphenols, phytoestrogens, phytosterols, phytates and polyunsaturated fatty acids. Most of them are featured by antioxidant properties. In the first part of this review, we indicate the main groups of bioactive compounds giving a description of their localisation, chemical properties and biological actions. Recently, it was shown, however, that the bioavailability of potential antioxidants from plant foods is generally too low to have any substantial direct effect on reactive oxygen species. As a result of that it is postulated that dietary compounds, even in very low concentrations, may have a far greater impact than previously appreciated on the regulation of gene expression. The second part of this paper concerns the action of the literally most important bioactive substances on the molecular mechanisms of the control of genes which in turn affect cellular metabolism. A few current studies on the action of selected nutraceuticals on the activity of transcription factors such as AP-1, NF- $\mathrm{BB}$, SREBPs, PPARs as final targets in the signal transduction cascade and gene regulation are included. A detailed analysis of numerous factors of dietary origin with their targets is far beyond the scope of this paper. However, continuing research on the effects of nutraceuticals on gene expression should provide insight into the mechanisms of prevention of diseases such as obesity, diabetes, atherosclerosis, hypertension and cancer by dietary manipulations.
\end{abstract}

bioactive compounds / antioxidants / transcription factors / AP-1 / NF- $\kappa$ B / PPARs / SREBPs / gene expression

\footnotetext{
* Correspondence and reprints

E-mail: ostaszewski@alpha.sggw.waw.pl
} 


\section{INTRODUCTION}

Wild primates, close relatives to humans, consume as a rule diets high in fiber, vitamins, minerals, and with variable levels of proteins and fatty acids [66]. Even in captivity but more in the wild, they spontaneously have plenty of exercise. In turn, the current lifestyles of humans almost everywhere in the world are in sharp contrast, and as a consequence, humans suffer from a large number of chronic diseases. In the past, infectious diseases killed our ancestors early on, often younger than age 40 , so they did not display the current epidemic of chronic diseases that arise in older ages. Now medical status has been improved. The problem of infectious diseases has been solved due to the amelioration of medical care (vaccination programs, antibiotics). Nowadays, people live longer and therefore express symptoms of chronic diseases associated with senescence and lifestyle (also called civilisation diseases) such as obesity, diabetes, hypertension, coronary heart disease, and cancer.

\section{NATURAL BIOACTIVE COMPOUNDS OF PLANTS}

Bioactive components of food which are of special interest include the following groups: polyphenols, phytoestrogens, phytosterols, phytates, lectins, oligosaccharides and polyunsaturated fatty acids (PUFA) [30]. These groups consist of many related compounds, each with slightly different properties. It is important to stress that the protection against cancer and cardiovascular disease is undoubtedly the result of the cumulative action of many natural substances present in the diet. Since each plant contains different bioactive components, the eating of various foods seems to be important but needs further evidence. Taking this into account, we may enjoy a lower risk of occurrence of modern diseases.

\subsection{Polyphenols}

Polyphenolic compounds are mainly found in fruits and vegetables and are one of the most important sources of bioactive components of the human diet [76] Over 8000 polyphenols have been identified and among them more than 2000 are found in nature. Plants need them for pigmentation, growth, reproduction, resistance to pathogens and for many other functions. One of the most important groups of polyphenols is flavonoids. They can be divided into the following subgroups: flavones/flavonones, anthocyanins and catechins/flavonols. In plants, flavonoids usually form complexes with various sugars which are called glycosides. Flavones/flavonones have been isolated from almost all fruits and vegetables with their highest concentrations being found in the outer layers. Therefore flavonoid consumption can be dramatically reduced if the peel of an apple is removed. However, there are fruits like oranges for example that have high amounts of flavonoids also present in the pulp. In most European countries, the average daily consumption of flavones/flavonones does not exceed $25 \mathrm{mg}$ per day. Anthocyanins are the largest group of water-soluble pigments in plants. They are widely distributed in the human diet through crops, beans, fruits, vegetables and red wine [31]. Tsuda et al. [98] showed that anthocyanins can inhibit the formation of the nitrated tyrosine and scavenge peroxynitrites. Moreover anthocyanins express a potent antioxidant activity and protective effect against hepatic ischemia-reperfusion injury in vivo.

Catechins are unique flavonoids found in large quantities in green tea. In black tea the level of catechins is about $30 \%$ that of green tea. Green tea extracts are described as protective against experimentally induced cancer in animals. They act as strong inhibitors of the in vitro nitrosation of secondary amines and therefore lower tumor initiation [94]. High amounts of catechins 
present in tea are also found in red wine and chocolate, which may contribute significantly to the daily intake of polyphenols [100]. It is estimated that the daily intake of polyphenols does not exceed $200 \mathrm{mg}$ per day, which is relatively high compared to the intake of other antioxidant nutrients, such as vitamins E, C or A. Polyphenolic compounds have beneficial health effects because of their antioxidant properties and their inhibitory role in the various stages of tumor development [38]. There are cohort studies indicating a possible protective action against coronary heart disease [49] and strokes [45]. Polyphenols act through the scavenging of free radicals (reactive oxygen species, ROS) and therefore are considered to be powerful antioxidants.

\subsection{Phytoestrogens}

Phytoestrogens have become one of the more topical areas of interest in clinical nutrition. They mimic human estrogens and therefore are considered as natural selective estrogen receptor modulators (SERMs) [90]. There are two subclasses of polyphenols (isoflavonoids and lignans) isolated from various plants [65]. The main consumable plant sources of phytoestrogens include isoflavonoids and lignans found mainly in soybeans and flaxseed, respectively. Other sources of phytoestrogens include sunflower and sesame seeds, various nuts, berries, garlic and carrots [86]. Plant lignans are also found in many cereals, grains, fruits and vegetables [6]. Since Asians consume a lot of soybean products, their daily isoflavonoid intake is $25-100 \mathrm{mg}$. In western Europe isoflavonoid consumption is usually a few mg per day due to a much lower intake of soybean products. Phytoestrogens may prevent cancer in humans. In countries with high consumption of soybean products the risk for hormone-related prostate and breast cancer is much lower than in populations with a low consumption of soybeans [68]. Phytoestrogens also protect against bowel and other non-hormonal cancers, cardiovascular diseases and osteoporosis [5]. Recently, Karamsetty et al. [46] found that soybean phytoestrogens genistein and daidzein act like estrogens in restoring nitric oxide-mediated relaxation in hypoxic rat pulmonary arteries and moreover, this effect is not mediated by the inhibition of tyrosine kinases.

It is recommended to consume moderate amounts of phytoestrogens in their natural form as plant foods. If their intake is too high they could be potentially harmful to human health although this is unlikely to happen.

\subsection{Phytosterols}

Phytosterols are bioactive non-nutrient substances structurally similar to cholesterol. They exist in two forms: (1) unsaturated, common, present in many plants and (2) saturated, called stanols, which are found only in small amounts in cereals, fruits and vegetables [71]. Northern European daily consumption of phytosterols is in the range $100-400 \mathrm{mg}$ and comes mainly from vegetable oils, bread, fruits and vegetables. In southern Europe the intake may be even higher as a result of high consumption of vegetable oils and nuts. The health effects of phytosterols are the result of their structural similarity to cholesterol; therefore plant sterols compete with cholesterol absorption from the intestinal tract. When typical amounts of sterols (240-320 mg) are consumed, only about $5 \%$ are absorbed from the small intestine [53]. Thus, the dietary intake of phytosterols causes an increased excretion of both dietary and biliary cholesterol in humans [35]. In addition to reducing the absorption of cholesterol, plant stanols inhibit the absorption of other plant sterols [32]. In humans, this inhibition of intestinal cholesterol absorption is accompanied by a compensatory increase in cholesterol synthesis, as reflected in the increase of serum cholesterol precursors, lathosterol 
and desmosterol. However, the net effect is still a reduction in serum cholesterol. The beneficial effects of vegetable oils are due to the high amount of phytosterols which lower serum cholesterol. Moreover, the interaction between dietary fibre and phytosterols could explain why diets rich in fibre may reduce the risk of coronary heart disease. The use of a special margarine increases the dietary intake of phytosterols to $1-3 \mathrm{~g}$ per day which is a therapeutic amount. In 1995, the Finns introduced plant stanol esters (PSE) in margarine, as dietary adjuncts to lower cholesterol by more than $10 \%$ [15].

\subsection{Phytates}

This group of bioactive substances is also called substances with antinutritional properties although this term is also appropriate for flavonoids.

Phytates are present in seeds which are an important source of plant phosphorus stored there in the form of phytic acid (myo-inositol hexaphosphate acid, InsP6) [61]. The antinutritional effects of phytic acid are primarily related to the strong chelating associated with its six reactive phosphate groups. Its ability to complex with proteins and particularly with minerals has been a subject of investigation from chemical and nutritional viewpoints [99]. High contents of phytates are observed in cereal grains, legumes and nuts whereas in vegetables their concentrations are low. The hydrolysis of phytates into inositol and phosphates or phosphoric acid occurs as a result of phytase action [79] or nonenzymatic cleavage, i.e. food processing [2]. Enzymes capable of hydrolysing phytates are widely distributed in micro-organisms, plants and animals. Phytases, naturally present not only in plant foods, but also in yeasts or other microorganisms implemented in food processing, act in a stepwise manner to catalyse the hydrolysis of phytic acid. To reduce or eliminate the chelating ability of phytate, dephosphorylation of hexa- and penta-phos- phate forms is essential since a high degree of phosphorylation is necessary to bind minerals. In developing countries where the diet is almost wholly based on cereals and legumes, iron and zinc deficiency are frequently observed. Phytate-related mineral deficiencies are also reported in people from developed countries, such as pregnant women, infants and adolescents. There are several methods of decreasing the inhibitory effect of phytic acid on mineral absorption (germination, fermentation, soaking, autolysis and malting). Unfortunately heat processing at home during cooking or during food manufacturing does not affect phytates. Therefore, the selection of starter cultures to improve phytate degradation is very important. In some cases, commercial phytase can be added to remove phytate, especially from infant foods.

In recent years, dietary phytate has received increased attention due to its role in cancer prevention and/or therapy and its hypocholesterolemic effect [54]. In turn, by binding an excess of free iron in the small intestine, phytates may prevent the formation of free radicals by the Fenton reaction in the colon and consequently decrease iron absorption for all who need less iron.

\subsection{Lectins}

In the past, the main scientific interest was focused on the toxicity of lectins, for example ricin. Nowadays, these bioactive compounds are recognized as natural components of the human diet. It has been shown that dietary lectins, which bind avidly and are endocytosed by cells of the brush border epithelium, are powerful growth factors for the gut [83], induce changes in its digestive/ absorptive functions, modify the state of glycosylation of luminal receptors, alter the expression of genes coding for digestive enzymes, transport and structural proteins and interfere with both the bacterial ecology and the immune response of the gut to food antigens. Furthermore, they stimulate 
pancreatic growth and have profound effects on the immune system [81]. Plasma cells involved in a multiplicity of immune functions express high and variable levels of endogenous membrane lectins, most of which are used in cell-to-cell communication.

\subsection{Oligosaccharides}

Oligosaccharides represent a structurally diverse class of macromolecules of a relatively widespread occurrence in nature. They are mainly present as glucans with different types of glycosidic linkages, while others mostly bind to protein residues as oligosaccharide-protein complexes [25]. The most promising biopharmacological activities of these biopolymers are their immunomodulation and anti-cancer effects. Oligosaccharides and oligosaccharide-protein complexes are considered as multicytokine inducers that are able to induce the gene expression of various immunomodulatory cytokines and cytokine receptors. Numerous anti-tumor polysaccharides have been discovered from mushrooms, fungi, yeasts, algae, lichens and plants and at present are intensively studied [75]. Fructooligosaccharides (FOS) are short-chain polymers of fructose which are produced commercially by hydrolysis of inulin or by enzymatic synthesis from sucrose or lactose. They are not hydrolyzed in the human small intestine but degraded in the colon by the resident microflora. They are mainly known for their ability to increase the endogenous growth of intestinal lactobacilli and bifidobacteria in humans and animals which is recognized as beneficial to health. [8]. In vivo studies in rats have shown that FOS increase the proportion of butyrate which in turn stimulates water and sodium absorption and modulates intestinal motility. FOS also increase $\mathrm{Ca}, \mathrm{Mg}$ and $\mathrm{Fe}$ absorption and enhance bone calcium stores in rats [74].

\subsection{Polyunsaturated Fatty Acids (PUFA)}

Polyunsaturated fatty acids consist of two parent compounds: linoleic acid, a fatty acid of the $\omega-6$ family with 18 carbon atoms and two double bonds (18:2n6) and $\alpha$-linolenic acid, a fatty acid of the $\omega-3$ family with 18 carbon atoms and 3 double bonds (18:3n3). These fatty acids have different metabolic effects. Linoleic acid (LA) can be elongated to arachidonic acid (AA), a fatty acid with 20 carbon atoms and 4 double bonds (20:4n6) with two intermediary metabolites termed $\gamma$-linolenic acid (18:3n6, GLA) and dihomo- $\gamma$-linolenic acid (20:3n6, DHLA) while $\alpha$-linolenic acid can be elongated to either eicosapentaenoic acid (EPA), a fatty acid with 20 carbon atoms and 5 double bonds (20:5n3) or docosahexaenoic acid (DHA), a fatty acid with 22 carbon atoms and 6 double bonds (22:6n3). The fatty acids with 20 carbon atoms, AA and EPA play an important role in prostaglandin metabolism and may influence the thrombotic process. Cohort studies [39] indicate that the intake of $\alpha$-linolenic acid is inversely related to coronary heart disease. Whether this effect is independent of other unsaturated fatty acids e.g. linoleic acid, is difficult to establish because different unsaturated fatty acids are present in the same foods e.g. soybean oil. However, the hypothesis of a protective effect of $\alpha$-linolenic acid in relation to coronary heart disease is supported by the results of the Lyon trial. In this intervention study, a Mediterranean diet enriched with $\alpha$-linolenic acid was strongly protective in relation to coronary heart disease [23, 84]. However, more data is needed before definite statements can be made about the possible protective effect of $\alpha$-linolenic acid.

\subsection{Other mechanisms of action}

A number of human intervention studies concerning antioxidant and/or anti-genotoxic effects of various polyphenols have shown 
no convincing results $[37,50,101]$. Also extensive studies with orally administered high rates of plant extracts rich in phenolics have failed to demonstrate antioxidant effects, except for a transient improvement in the amount of trapped free radicals [49, 107]. According to estimated daily intake of flavonoids, the range of 100-200 mg.day ${ }^{-1}$ is a very low level when compared with the levels used in the aforementioned studies. Recent work has shown that the bioavailability of potential antioxidants is too low to have any substantial direct effect on reactive oxygen species (Fig. 1). Moreover, the vast number of phenolics present in foodstuffs are glycosides and the free radical scavenging activity decreases with the presence of a sugar moiety, so glycosides are not antioxidants, although their corresponding aglycons are. However, it is well recognized that many polyphenols that do not show antioxidant effects show antiinflammatory, anti- or pro-estrogenic, antimutagenic and anti-carcinogenic effects Therefore, it is postulated that dietary compounds, even in very low concentrations, may have a far greater impact than previ- ously anticipated, most likely by the regulation of gene expression. This in turn can affect cellular metabolism with profound effects on detoxification mechanisms and cell proliferation, differentiation, survival and death.

On the contrary, deleterious effects of polyphenolic compounds have also been observed, and are associated with the ability to bind and precipitate macromolecules including protein and carbohydrates and reduce the digestibility of food. The colouring pigments in plants called flavonoids are the best known and best characterized of these groups. Flavonoids have been considered antinutrients because they have been shown to inhibit the activity of a wide range of enzymes including digestive enzymes such as hydrolases, but also isomerases, oxygenases, oxidoreductases, polymerases, phosphatases, protein kinases and amino acid oxidases. Failure to scavenge free radicals in vitro does not necessarily mean that some flavonoids will not trigger biological effects in vivo. Flavonoids might interfere with various transduction signal cascades

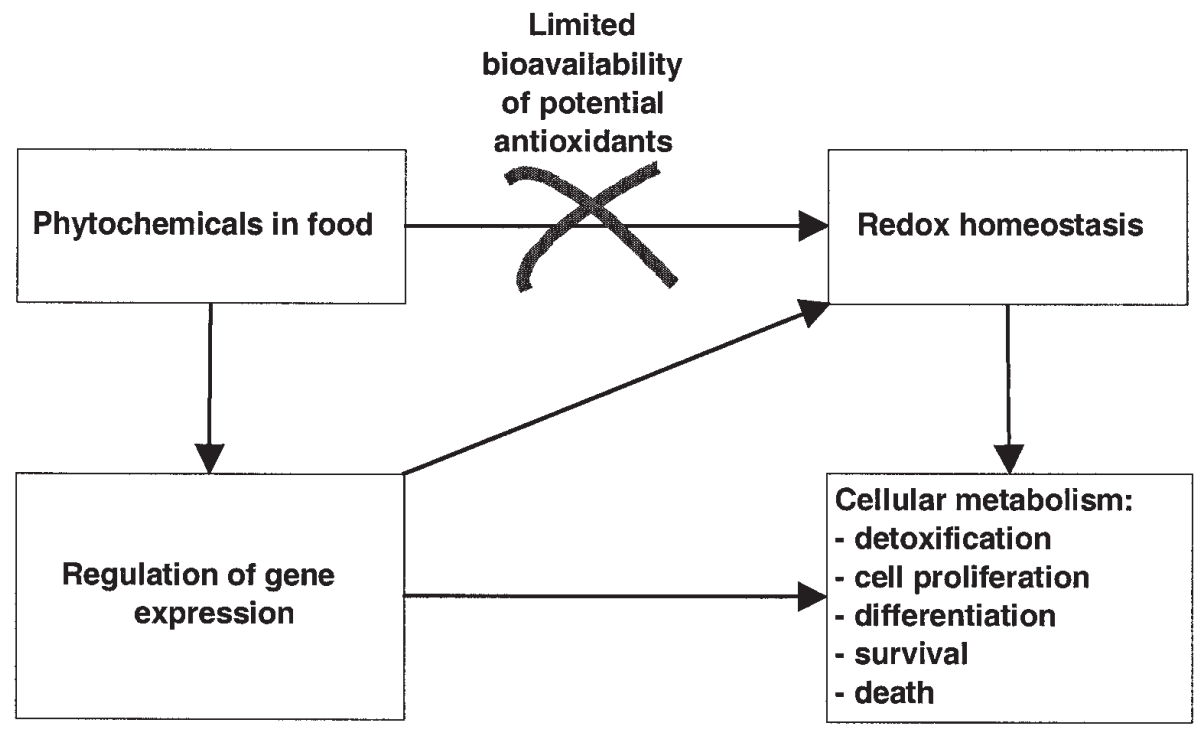

Figure 1. Relationship between bioavailibility of potential antioxidants and cell functions. 
by affecting the eicosainoid synthesis via cyclooxygenase/lipoxygenase pathways [56], or protein tyrosine kinases [40, 85]. Some of them may also form complexes with metal cations, thereby interfering with the absorption of minerals such as iron or copper [14]. The ability to bind minerals may be beneficial in some cases, since copper and iron are the initiators of hydroxyl radical formation by the Fenton reaction [96]. Except in extreme cases, undernourishment in western societies may actually lead to beneficial effects such as the prevention of obesity and genomic stability.

\section{IMPACT ON GENOMICS}

Polyphenols including flavonoids are to be considered as xenobiotics and as such may profoundly affect the activation and excretion of exogenous carcinogens. Certain polyphenols may directly or indirectly induce phase II enzymes such as glutathione transferases (GSTs), NAD(P)H:quinone reductases, epoxide hydrolases, and UDPglucuronosyltransferases that will enhance the excretion of oxidising species [29, 108]. Concomitantly, flavonoids significantly decrease the activity of antioxidant enzymes glutathione reductase (GR), catalase (CAT) and glutathione peroxidase (GPx) in the red blood cells of rats [11]. They are also reported to influence the expression and the activity of cytochrome P450 (CYP) [19, 104]. Antioxidant activities have shown little or no relationship to the above-mentioned antimutagenic/anticarcinogenic activities of flavonoids [34].

How do flavonoids induce such numerous and multidirectional modifications in the intracellular biochemical apparatus? It seems likely that the effects of some of them may indirectly occur through the action on response elements in the regulatory regions of the genes. The xenobiotic response element (XRE) is localized in the promoter regions of several genes encoding proteins such as xenobiotic metabolizing enzymes
(XME) of phase I (CYP1A1, CYP1A2), and phase II (NADP(P)H-menadione oxidoreductase, aldehyde dehydrogenase, UDPglucuronosyl-transferase, glutathione S-transferase) xenobiotic elimination. There are specific transcription factors, which in turn specifically bind to XRE. Once activated by the assembly with aromatic hydrocarbons or halogenated derivatives such as dioxin (TCDD), the cytosolic protein called the aryl hydrocarbon receptor (AhR) translocates to the nucleus where it heterodimerizes with the aryl hydrocarbon nuclear translocator forming a transcription factor that binds to the XREs present in the 5'-promoter [33]. Dietary flavonoids are ligands of the AhR and affect cyplal expression, with quercetin being a very potent activator whereas kaempferol and green tea polyphenols (GTP) - catechins; especially (-)-epigallocatechin gallate (EGCG) inhibit cyplal transcription induced by TCDD [19, 104]. Alternatively, flavonoids are reported to act through the transcriptional regulation of genes by directly affecting the antioxidant/oxidant response element (ARE/ORE) in the promoter regions of some of the genes (gstal, cypla1, cypla2) of the XME [108]. It should be noted that ARE/ORE is the electrophile response element, so flavonoids may act directly on ARE/ORE as phenolic radicals or indirectly by the effects on oxidative stress. Flavonoids have been observed to repress intrinsic antioxidant systems as a feedback mechanism exerted on antioxidant enzymes eventually pointing to the importance of intracellular prooxidantantioxidant homeostasis.

There are promoter regions of several genes (including XME) that posses another response element that is activated by glucocorticoid and glucocorticoid-like structures. This, termed the glucocorticoid response element (GRE) is induced either by the glucocorticoid receptor-ligand transcription factor or by the glucocorticoid receptor-independent mechanism [60]. There is also the possibility that transcription factors formed by the glucocorticoid receptor-glucocorticoid 
interaction influence XRE the regulation of gene expression. Flavonol quercetin has been reported to selectively inhibit GREdependent gene regulation [58].

The activation of xenobiotic response elements by dietary agents has been known for some time, but the effects driven by the antioxidant response elements and through nuclear transcription factors such as AP-1 and nuclear factor kappa B (NF-кB) families are only now being recognized.

\subsection{Modulation of signal transduction cascades}

One important mechanism of regulation appears to be the inhibition by dietary agents of one or more of the kinase families of enzymes involved in the respective signal transduction. This may occur either by direct inhibition of the kinases itself or via the redox sensitivity of the kinase protein. At present, little is known about the molecular mechanisms of specific genes coding for proteins responsible for the observed beneficial health effects of flavonoids. The candidates to play the key role in the regulation of cell life and death at the transcriptional level includes NF- $\kappa \mathrm{B}$ and AP-1 transcription factors. Conflicting data describe the effects of catechins and teaflavins on the activation of extracellular signal-regulated kinase (ERK2) and c-Jun N-terminal kinase (JNK1) and the expression of c-jun and c-fos mRNA as well as the activity of the activator protein 1 (AP-1) (Fig. 2). There is also contradicting evidence for the induction of AP-1 and NF- $\mathrm{BB}$ by the

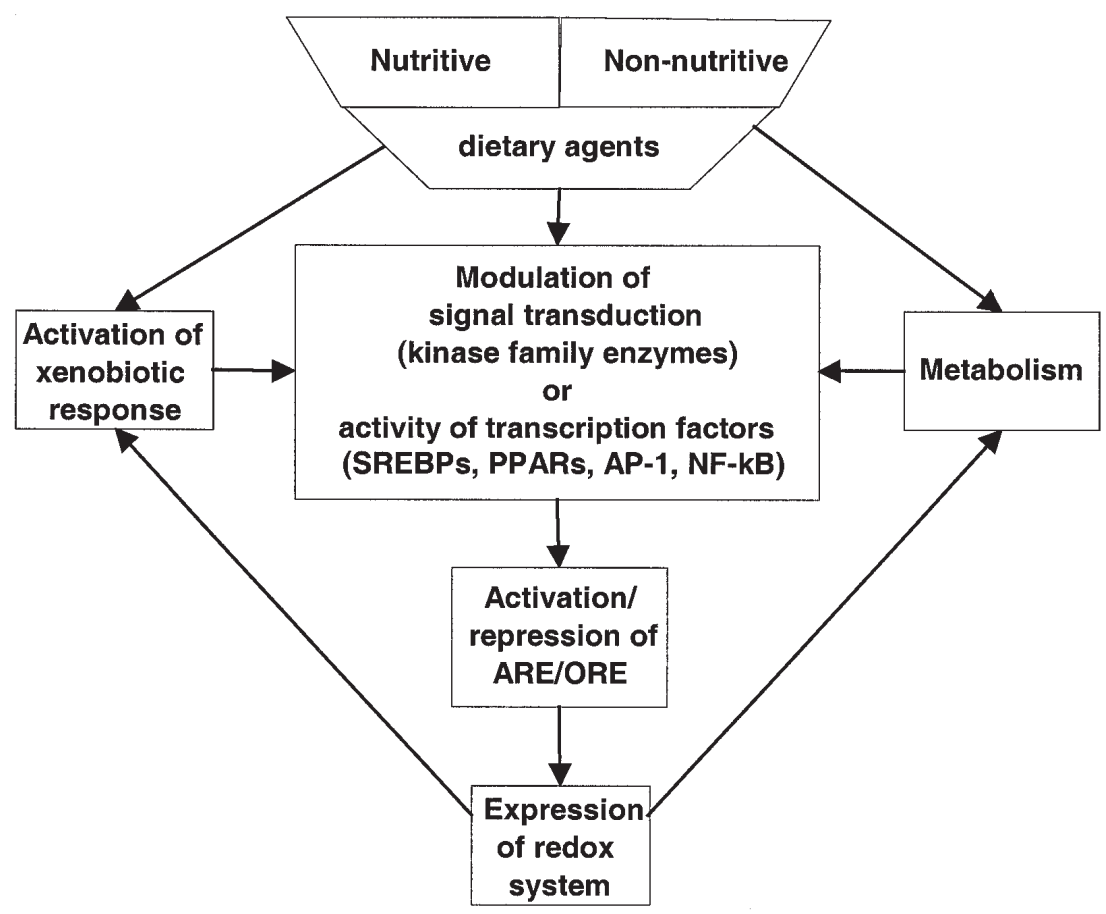

Figure 2. Suggested metabolic pathway of nutritive and non-nutritive dietary agents. NF- $\kappa \mathrm{B}-$ nuclear factor kappa B; AP-1 - activating protein-1, PPARs - peroxisome proliferator-activated receptors; SREBPs - sterol regulatory element - binding proteins; ARE/ORE - antioxidant response element/oxidant response element. 
commercially used phenolic antioxidants butylated hydroxyanisol (BHA) and $t$-butylhydroquinone (tBHQ). They either activate NF- $\kappa \mathrm{B}$ (measured by the electrophoretic mobility shift assay) with the formation of $\mathrm{H}_{2} \mathrm{O}_{2}$ [82], or phenoxyl radicals and/or their derivatives [51] or inhibit NF- $\kappa \mathrm{B}$ DNA binding [10]. Phenolics trigger c-Jun N-terminal kinase (JNK1) and/or extracellular signal regulated protein kinase (ERK2) in a dose-dependent fashion [108]. In contrast to $\mathrm{Yu}$ et al. [108] who observed activation, Chung et al. [18] found the inhibition of ERK2, JNK1, and AP-1 activity. Since JNKs are strongly and preferentially activated by stress stimuli, this signaling pathway as one of the stress responses and is functionally involved in cellular survival and/or apoptosis [47]. It is probable that the effect of quercetin is also dose-dependent on the regulation of MAPKs and leads to the induction/repression of gene expression and cell survival or cell death. At certain levels quercetin might be an indirect $\mathrm{NF}-\kappa \mathrm{B}$ inducer by targeting several kinases (i.e. MAP kinases), which activate NF- $\kappa$ B. Upstream activators include NIK, MEKK1, MEKK2, MEKK3, TAK1, protein kinase $\mathrm{C} \zeta$, and S6 kinase $[55,69,72,88$, 112]. Similarly, contradicting results were obtained from studies with quercetin and

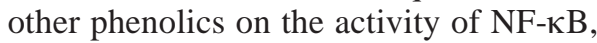
the key regulator of cellular antioxidant defence systems. Sato et al. [87] or Ishikawa et al. [43] reported the suppression of NF-кB activation by quercetin in human synovial cells, or glomerular cells, respectively, but the cells were studied in serum free medium, with additional one day fasting as the pretreatment period to induce cell quiescence. We reported transient activation of this transcription factor by quercetin in conditions favoring cell proliferation [77]. It therefore appears, that quercetin-induced NF- $\mathrm{BB}$ activation is characterized by cell specificity. Actually, phenolic antioxidants at high doses also activate ICE/Ced-3 caspases [51, 52]. An NF-кB RelA/p65 subunit acts as a signal from cytosol, which initiates transcription mechanisms leading to the enhanced expression of genes responsible for cell resistance to stress and apoptosis. The chemical structure of flavonols is characterized by the presence of the 2-phenylbenzen- $\gamma$-pyron ring. The ultimate difference between quercetin and kaempferol is confined to the presence of an additional hydroxyl $(\mathrm{OH})$ residue in the 3 ' position of the $\mathrm{B}$ ring $[1,95]$. Thus, one who compares the effect of quercetin or kaempferol on colorectal cancer cells might easily distinguish the role of the hydroxyl group present or absent in the particular flavonol. Anticarcinogenic properties of flavonols resulted in part from the inhibition of NF- $\kappa \mathrm{B}$ activity [78]. NF- $\kappa \mathrm{B}$ is a ubiquitous regulator of transcription in almost every cell and it modulates the activity of genes that are characterized by the presence of the $\mathrm{NF}-\kappa \mathrm{B}$ consensus sequence in the regulatory (enhancer/promotor) regions of DNA [9]. Activation of NF- $\kappa$ B has been reported to suppress cell death, while the blockade leads to the amplification of the cytotoxic effects of TNF- $\alpha$ and promotes apoptosis [113]. When stimulated, NF- $\kappa \mathrm{B}$ promotes transcription, whereas the inactive form resides within the cytoplasm, blocked by the I $\mathrm{B}$ subunit (with the exception of lymphocytes - B cells, where NF- $\kappa \mathrm{B}$ is constitutively expressed in the nucleus) [26, 64]. According to the differences in the structure, at least five isoforms of NF- $\mathrm{KB}$ have been identified but the most abundant are subunits p50 and p65 that form homo- or heterodimers which can bind to DNA [64]. On the contrary, TNF- $\alpha$ is a proinflammatory cytokine, which is known to induce cell death. TNF- $\alpha$ acts on the cell by the activation of the membrane receptors TNF-R1 or TNF-R2. Association with the receptors leads to conformational changes (oligomerization into trimers) and the receptors are able to recruit a signaling complex called the DISC (death-initiated signaling complex) composed of the TRADD (TNF-R1associated death domain) and FADD (Fasassociated death domain). Simultaneously or alternatively, conformational changes in 
the receptors can recruit a signaling complex composed of TRADD and TRAF2 (TNF-associated factor 2) and/or RIP (receptor interacting protein) for survival [91]. After the association, TRAF2 and RIP could activate kinase NIK (NF- $\kappa \mathrm{B}$ inducing kinase) that stimulates NF- $\mathrm{KB}$ indirectly by the activation of IкB $\alpha$ or $-\beta$ kinases (IKK $\alpha$, IKK $\beta$ ). IKK $\beta$ kinase i.e. phosphorylates the I $\mathrm{B} \alpha$ inhibitory subunit in positions 32 and 36 of serine residues. After phosphorylation I $\kappa \mathrm{B} \alpha$ can be ubiquitinated and proteolytically degraded by the proteasome. Thus, $\mathrm{NF}-\kappa \mathrm{B}$ is not sequestered any more and translocates into the nucleus [10, 26, 47, 59, 91]. NF- $\kappa B$ activation improves cell survival whereas inhibition enhances cytopathic and apoptotic effects of TNF- $\alpha$ indicating a considerable role of functional NF- $\kappa \mathrm{B}$ in cell viability. The protective effect of $N F-\kappa B$ is in turn dependent on mRNA and proteins that regulate the activity of antiapoptotic genes. Obviously, NF- $\kappa \mathrm{B}$ directly activates Bcl-2/A1 (a homologue of Bcl-2) the protein that plays an important role in the blockade of apoptosis associated with the activity of the mitochondria [113]. Additionally, the activation of TNF-R1 by TNF- $\alpha$ is associated with the increased activity of PI-3K and $\mathrm{PKB}$, the most powerful antiapoptotic kinases. On the contrary, the inhibition of $\mathrm{NF}-\kappa \mathrm{B}$ was shown to occur as a consequence of proteasome inhibitors, corticosteroids, and factors that are known to block NIK and IKK [36], as well as under the influence of STAT-1, a tyrosine kinase that appears to be a component of the signaling complex of TNF-R1 and TRADD. Apparently, STAT-1 is recruited by TNF-R1 and enables the formation of the DISC complex; furthermore it reveals apoptotic domains of death-mediating proteins with the concomitant inhibition of the assembly of the survival complex, which releases NF- $\mathrm{B}$ [103]. Substantial interest to study the physiological role of the STAT-1 resulted from its dual role as the non-receptor tyrosine kinase and transcription factor (the STAT acronym stands for that meaning). One should bear in mind, however, that flavonoids are known as the most powerful inhibitors of tyrosine kinases. Whether flavonols are potent inhibitors/activators of STAT-1 and effect signal transduction form TNF- $\alpha$ to NF- $\mathrm{NB}$ with simultaneous activation of genes supporting cell viability, is a matter of debate and needs experimental verification which is currently in progress in our laboratory.

The developing resistance of tumor cells to chemotherapy is a challenge to contemporary medicine. A number of drug resistance mechanisms are not known as well as the origin of this phenomenon. Apparently, apoptosis is a hallmark of an efficient cytotoxic effect of chemotherapy or radiation therapy. Apoptosis is also widely accepted as a mechanism leading to cell elimination induced by TNF- $\alpha$. Therefore, TNF- $\alpha$ either/ or chemotherapy as well as radiation therapy might be considered as important activators

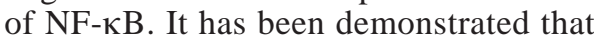
inhibition of NF- $\mathrm{\kappa B}$ supports the therapies based on the action of TNF- $\alpha$ [7, 102]. A marked role of NF- $\kappa \mathrm{B}$ has been observed in developing resistance to chemotherapy in the following cases: Hodgkin lymphoma, juvenile myelomonocytic leukemia, prostate cancer, virus-mediated leukemic T cells and tumor cells transformed with Ras oncogene. Tumor cells are also characterized by a higher nuclear representation of NF-кB, moreover the genes regulated by NF- $\kappa \mathrm{B}$ are often constitutively upregulated in neoplasmas [59, 70, 93]. NF-кB is thus linked to tumor growth, because it inhibits apoptosis. Several experimental data support the evidence of a profound role played by $N F-\kappa B$ in TNF- $\alpha$-mediated apoptosis. Overexpression of IкB renders tumor cells significantly less susceptible to TNF- $\alpha$-induced cell death [28]. The reaction was observed in tumor cell lines such as Jurkat T cells, human urine bladder line T24 and breast cancer MCF7. On the contrary, flavonoids are cytopathic to tumor cells. The puzzling issue of the developing resistance of tumor cells to cytopathic actions of flavonols in the presence of TNF- $\alpha$-stimulated NF- $\kappa$ B activity remains unexplained and ambiguous [77]. 
Another possible mechanism of cell toxicity of flavonoids seems to be quite similar to that reported by Serrano et al. [89] for other phenolic compounds such as gallic acid and its esters, which inhibit protein tyrosine kinases (PTKs). Similar findings were obtained by Kawada et al. [48] on the basis of studies with quercetin and resveratrol in cultured rat stellate and Kupfer cells. In their studies, the action of quercetin aglycon was associated with suppressed inositol phosphate metabolism, tyrosine phosphorylation, reduced level of cell cycle protein cyclin D1 and mitogen-activated (MAP) kinase activation in PDGF/BB stimulated stellate cells.

In certain cases quercetin aglycon could promote tumorigenesis and tumor growth [62] possibly by oxidative DNA damage in the presence of $\mathrm{Cu}^{2+}$ [106]. We suggest that the anticarcinogenic activity of quercetin aglycon is dose dependent and is influenced by the presence of cytotoxic agents as well as serum survival factors (cytokines, oxygen free radicals - OFR) $[63,86]$. Phenolics stay in the first line of antioxidant defence, donating electrons to OFR with a resultant formation of phenoxyl radicals [16]. Prooxidant phenoxyl radicals co-oxidise NADH and GSH, which in turn are no longer able to inhibit NF-kB activation [17]. It appears that apoptosis may be initiated by phenolics. According to recent advances in the interpretation of events that occur during programmed cell death, the generation and spreading of ROS within the cell are consequences of the increased permeability of the mitochondrial membrane [80, 109]. Lepley and Pelling [57] during a novel cell culture study with apigenin (a quercetin derivative), obtained evidence that flavonoid antioxidants may enhance apoptosis in certain tumor cell lines. Hydrogen peroxide $\left(\mathrm{H}_{2} \mathrm{O}_{2}\right)$, similarly to quercetin has been reported to stimulate the activity of the mitogen-activated protein kinases (MAPKs) ERK and JNK, and the expression of the proto-oncogenes c-fos and c-jun [97]. Cell elimination or survival is then a matter of balance between the protein products of genes controlling cell life and death. The key roles whether an individual cell dies or remains alive may be the modulation of antioxidant defences [12]. Quercetin has been suggested to be beneficial for health, however, studies have shown that many antioxidants can also exhibit, a prooxidant behavior [16, 24]. Plant polyphenols including quercetin aglycon may interfere with the cellular redox state by the inhibition of glutathione reductase [110] and the efflux of glutathione S-conjugates [111]. The final effect of plant phenolics on the viability of cells is therefore variable. At low concentrations quercetin and derivatives seem to exert a stimulatory action on cell viability and survival, whereas at high doses $(100 \mu \mathrm{M}$ and higher) they are apoptogenic and cytotoxic $[3,4,51,52,85]$. From a dietary point of view, it remains to be established what doses could be considered as beneficial for health.

\subsection{PUFA as ligands of transcription factors}

The development of obesity and associated insulin resistance involves a multitude of gene products, including proteins involved in lipid synthesis and oxidation, thermogenesis and cell differentiation [20]. The dietary $\omega-6$ and $\omega-3$ polyunsaturated fatty acids (PUFA) suppress lipogenesis in the liver while they simultaneously induce the transcription of genes encoding proteins of lipid oxidation and thermogenesis [21]. Furthermore, the lipoprotein metabolic pathway is altered by peroxisome proliferatoractivated receptors (PPARs). The PPARs are a member of the steroid hormone receptor superfamily. Three types of PPARs have been described: PPAR $\alpha, \operatorname{PPAR} \beta / \delta$ (Nuc1), and PPAR $\gamma$. PPAR $\alpha$ and PPAR $\beta$ are ubiquitously expressed in body tissues that predominantly catabolize fatty acids (i.e. heart, liver, muscle, brown adipose tissue) whereas PPAR $\gamma$ is selectively expressed in adipose 
tissues (recently found in other tissues including skeletal muscle) and seems to be associated with the differentiation of adipocytes. PPAR $\alpha$ is activated by PUFA such as eicosapentaenoic acid ( $\omega-3$; EPA) or linoleic acid ( $\omega-6, \mathrm{LA})$ and heterodimerizes with the 9-cis-retinoic acid receptor $(\mathrm{RXR} \alpha)$. After ligand binding (EPA), it functions as a transcription factor in the regulation of adipogenesis and insulin-mediated glucose transport. There is a positive correlation between the expression of $\mathrm{Cu}, \mathrm{Zn}$ dependent superoxide dismutase (SOD-1) and PPAR $\alpha$ [42]. Moreover, the same group observed that an increased liver PPAR $\alpha$ mRNA level confers a reduction of the plasma TBARS levels indicating the causative role of reactive oxygen species in the pathology of insulin resistance [41]. PUFA are not only strong ligands to PPAR $\alpha$, but also strong activators of PPAR $\gamma$ and PPAR $\beta$ [13]. Ligand binding enhanced the interaction of PPAR with its DNA-binding domains [44] called the PPAR response element (PRE). Functional PRE that reside in the 5'-flanking region have been found to exist in several genes including those involved in the oxidation of fatty acids and thermogenesis (uncoupling proteins UCP-1 and UCP-3), thus additionally supporting the evidence for its anti-diabetic and antiobesity function [27, 92]. Repartitioning of metabolic fuels away from storage and towards oxidation reflects the fact that PUFA co-ordinately suppress the transcription of lipogenic genes, while simultaneously inducing the transcription of genes encoding proteins of lipid oxidation ( $\beta$-oxidation of fatty acids) and thermogenesis [20, 22]. This effect of PUFA is in turn mediated by the transcriptional and translational suppression of another group of transcription factors termed sterol regulatory elementbinding proteins (SREBPs) [73, 105]. Thus, PUFA play a beneficial role in health by a hypolipidemic action by lowering plasma cholesterol and preventing atherosclerosis, hypertension, cardiovascular diseases, obesity and insulin resistance. This is further corroborated in studies performed by Mohan et al. [67], who observed that oral supplementation with oils rich in $\omega-3$ and $\omega-6$ PUFA could protect animals against alloxaninduced diabetes mellitus. It is thought that PUFA exert the aforementioned effect by enhancing the antioxidant status and suppressing the production of cytokines (TNF$\alpha$ in particular). Apparently, PUFA play a role as intrinsic ligands in activating the PPAR $\gamma$ - transcription factor, which up to date has been known to be activated merely by thiazolidinediones (antidiabetic drugs).

\section{PERSPECTIVES}

In recent years research has been revolutionized by the implementation of rapidly developing technologies. Examples are the construction of DNA/RNA arrays, the development of proteomics, the widespread availability of probes for important signal molecules, the insertion of reporter genes downstream of regulatory sequences and the use of gene knock-out models. All of these are having a major impact on the study of disease and disease development at the genome level. The same technologies are providing a unique opportunity for establishing the role of diet and dietary agents in protecting humans against diseases and disorders. The effects of food-derived compounds on the regulation of a broad spectrum of metabolic activities can thus be investigated, often simultaneously.

\section{ACKNOWLEDGEMENTS}

This work was supported by a grant No 3 P06T 05422 from the State Committee for Scientific Research in Poland.

\section{REFERENCES}

[1] Ader P., Wessmann A., Wolffram S., Bioavailability and metabolism of the flavonol quercetin in the pig, Free Radic. Biol. Med. 28 (2000) 1056-1067. 
[2] Agte V., Joshi S., Khot S., Paknikar K., Chiplonkar S., Effect of processing on phytate degradation and mineral solubility in pulses, J. Food Sci. Technol. 35 (1998) 330-332.

[3] Agullo G., Gamet L., Besson C., Demigne C., Remesy C., Quercetin exerts a preferential cytotoxic effect on active dividing colon carcinoma HT29 and Caco-2 cells, Cancer. Lett. 87 (1994) 55-63.

[4] Agullo G., Gamet Payrastre L., Fernandez Y., Anciaux N., Demigne C., Remesy C., Comparative effects of flavonoids on the growth, viability and metabolism of a colonic adenocarcinoma cell line (HT29 cells), Cancer. Lett. 105 (1996) 61-70.

[5] Arjmandi B.H., Alekel L., Hollis B.W., Amin D., Stacewiczsapuntzakis M., Guo P., Kukreja S.C., Dietary soybean protein prevents bone loss in an ovariectomised rat model of osteoporosis, J. Nutr. 126 (1996) 161-167.

[6] Ayres D.C., Loike J.D., Lignans: chemical, biological and clinical properties in Chemistry and Pharmacology of Natural Products, Cambridge University Press, Cambridge, 1990, pp. 47-52.

[7] Bakker T.R., Reed D., Renno T., Jongeneel C.V., Efficient adenoviral transfer of NF-KB inhibitor sensitizes melanoma to tumor necrosis factor - mediated apoptosis, Int. J. Canc. 80 (1999) 320-323.

[8] Blay G.L., Michel C., Blottiere H.M., Cherbut C., Prolonged intake of fructo-oligosaccharides induces a short-term elevation of lactic acidproducing bacteria and a persistent increase in cecal butyrate in rats, J. Nutr. 129 (1999) 2231-2235

[9] Botchine G.J., Geimonen E., Bilof M.L. Villarreal O., Tracey K.J., Loss of NF-KB activity during cerebral ischemia and cytotoxity, Mol. Med. 5 (1999) 372-381.

[10] Bowie A., O'Neill L.A.J., Oxidative stress and nuclear factor- $\kappa \mathrm{B}$ activation, Biochem. Pharmacol. 59 (2000) 13-23.

[11] Breinhold V., Lauridson S.T., Dragsted L.O., Differential effects of dietary flavonoids on drug metabolising and antioxidant enzymes in female rat, Xenobiotica 29 (1999) 1227-1240.

[12] Briehl M.M., Baker A.F., Siemakowski L.M., Morreale J., Modulation of antioxidant defences during apoptosis, Oncology Res. 9 (1997) 281-285.

[13] Brun R.P., Kim J.B., Hu E., Altiok S., Spiegelman B.M., Adipocyte differentiation: a transcriptional regulatory cascade, Curr. Opin. Cell Biol. 8 (1996) 826-832.

[14] Brune M., Rossander L., Hallberg L., Iron absorption and phenolic compounds: importance of different phenolic structures, Eur. J. Clin. Nutr. 43 (1989) 547-548.

[15] Cater N.B., Grundy S.M., Lowering serum cholesterol with plant sterols and stanols. Historical perspectives, in: Nguyen T.T. (Ed.), New
Developments in the Dietary Management of High Cholesterol Health Care Information Programs, McGraw-Hill Health Care Publications Group (Postgraduate Medicine Special Report) Minneapolis, 1998, pp. 6-14.

[16] Chan T., Galat G., O'Brien P.J., Oxygen activation during peroxidase catalysed metabolism of flavones or flavonones, Chemico-Biological Interact. 122 (1999) 15-25.

[17] Cho S., Urata Y., Iida T., Goto S., Yamaguch M., Sumikawa K., Kondo T., Glutathione downregulates the phosphorylation of IкB: Autoloop regulation of the NF- $\mathrm{\kappa B}$-mediated expression of NF- $\kappa B$ subunits by TNF- $\alpha$ in mouse vascular endothelial cells, Biochem. Biophys. Res. Commun. 253 (1998) 104-108.

[18] Chung J.Y., Huang C., Meng X., Domg Z., Yang C.S., Inhibition of activator protein 1 activity and cell growth by purified green tea and black tea polyphenols in H-ras-transfected cells: structure-activity relationship and mechanisms involved, Cancer Res. 59 (1999) 4610-4617.

[19] Ciolino H.P., Daschner P.J., Yeh G.C., Dietary flavonols quercetin and kaempferol are ligands of the aryl hydrocarbon receptor that affect cypla1 transcription differentially, Biochem. $\mathrm{J}$ 340 (1999) 715-722.

[20] Clarke S.D., Polyunsaturated fatty acid regulation of gene transcription: a mechanism to improve energy balance and insulin resistance, Br. J. Nutr. 83 (2000) S59-S66.

[21] Clarke S.D., Armstrong M.K., Jump D.B. Dietary polyunsaturated fats uniquely suppress rat liver fatty acid synthase and S14 mRNA content, J. Nutr. 120 (1990) 225-232.

[22] Clarke S.D., Baillie R., Jump D.B., Nakamura M.T., Fatty acid regulation of gene expression: its role in fuel partitioning and insulin resistance, Ann. New York Acad. Sci. 827 (1997) 178-187.

[23] De Lorgeril M., Renaud S., Mamelle N., Salen P., Martin J.L., Monjaud I., Gudiollet J., Touboul P., Delaye J., Mediterranean alpha-linolenic acid-rich diet in secondary prevention of coronary heart disease, Lancet 343 (1994) 1454-1459.

[24] Decker E.A., Phenolics: Prooxidants or antioxidants, Nutr. Rev. 65 (1997) 396-398.

[25] Delzenne N.M., Roberfroid M.R., Physiological effects of non-digestible oligosaccharides, Lebensm-Wiss-u-Technol. 27 (1994) 1-6.

[26] Deptala A., Bender E., Gorczyca W. Darzynkiewicz Z., Activation of nuclear factor kappa B (NF- $\mathrm{KB})$ assayed by laser scanning cytometry (LSC), Cytometry 33 (1998) 376-382.

[27] Field C.J., Ryan E.A., Thomson A.B.R., Clandin M.T., Diet fat composition alters membrane phospholipid composition, insulin binding and glucose metabolism in adipocytes from control and diabetic animals, J. Biol. Chem. 265 (1990) 11143-11150. 
[28] Freemerman A.J., Gallegos A., Powis G., NF-кB transactivation is increased but is not involved in the proliferative effects of thioredoxin overex pression in MCF-7 Breast Cancer Cells, Canc. Res. 59 (1999) 4090-4094.

[29] Galijatovic A., Walle U.K., Walle T., Induction of UDP-glucuronosyl-transferase by the flavonoids chrysin and quercetin in Caco-2 cells, Pharmaceutical Res. 17 (2000) 21-26.

[30] Gee J., Hurrell R., Leth T., Sandberg A-S., Food for Health - an insight into natural bioactive compounds of plants, in: Frolich W., Dokkum W.V., Chesson A. (Eds.), Cost 916 Action, Office for Official Publications of the European Communities, 2001

[31] Glories Y., Anthocyanins and tannins from wine: organoleptic properties, Prog. Clin. Biol. Res. 280 (1988) 123-134.

[32] Gylling H., Puska P., Vartiainen E., Miettinen T.A., Serum sterols during stanol ester feeding in a mildly hypercholesterolemic population, J. Lipid. Res. 40 (1990) 593-600.

[33] Hankison O., The aryl hydrocarbon receptor complex, Ann. Rev. Pharmacol. Toxicol. 35 (1995) 307-340.

[34] Hatch F.T., Lightstone F.C., Colvin M.E., Quantitative structure-activity relationship of flavonoids for inhibition of heterocyclic amine mutagenicity, Environ. Mol. Mutagen. 35 (2000) 279-299.

[35] Heinemann T., Kullak-Ublick G.A., Pietruck B., von Bergmann K., Mechanisms of action of plant sterols on inhibition of cholesterol absorption. Comparison of sitosterol and sitostanol, Eur. J. Clin. Pharmacol. 40 (Suppl. 1) (1991) S59-S63.

[36] Ho E., Bray T.M., Antioxidants, NF-кB activation and diabetogenesis, Soc. Exp. Biol. Med. 222 (1999) 205-213.

[37] Hodgson J.M., Puddey I.B., Croft K.D., Mori T.A., Rivera J., Beilin L.J., Isoflavonoids do not inhibit in vivo lipid peroxidation in subjects with high-normal blood pressure, Atherosclerosis 145 (1999) 167-172.

[38] Hollman P.C.H., Katan M.B., Dietary flavonoids Intake, health effects and bioavailability, Food and Chemical Toxicology 37 (1999) 937-942.

[39] Hu F.B., Stampler M.J., Manson J.A.E., Rimm E.B., Wolk A., Colditz G.A., Hennekens C. Willett W.C., Dietary intake of alfa-linolenic acid and risk of fatal ischemia heart disease among woman, Am. J. Clin. Nutr. 69 (1999) 890-897.

[40] Huang Y.T., Hwang J.J., Lee P.P., Ke F.C., Huang J.H., Huang C.J., Kandaswami C., Middleton E. Jr., Lee M.T., Effects of luteolin and quercetin, inhibitors of tyrosine kinases, on cell growth and metastasis-associated properties in A431 cells overexpressing epidermal growth factor receptors, Br. J. Pharmacol. 128 (1999) 999-1010.
[41] Inoue I., Noji S., Shen M.Z., Takahashi K., Katayama S., The peroxisome proliferator-activated receptor $\alpha(\mathrm{PPAR} \alpha)$ regulates the plasma thiobarbituric acid-reactive substances (TBARS) level, Biochem. Biophys. Res. Commun. 237 (1997) 606-610.

[42] Inoue I., Goto S.I., Matsunaga T., Nakajima T. Awata T., Hokari S., Komoda T., Katayama S. The ligands/activators for peroxisome proliferator-activated receptor $\alpha$ (PPAR $\alpha)$ and PPAR $\alpha$ increase $\mathrm{Cu}^{2+}, \mathrm{Zn}^{2+}$-superoxide dismutase and decrease p22phox message expressions in primary endothelial cells, Metabolism 50 (2001) 3-11.

[43] Ishikawa Y., Sugiyama H., Stylianou E., Kitamura M., Bioflavonoid quercetin inhibits interleukin-1-induced transcriptional expression of monocyte chemoattractant protein-1 in glomerular cells via suppression of nuclear factor-кB, J. Am. Soc. Nephrol. 10 (1999) 2290-2296.

[44] Issemann I., Green S., Activation of a member of the steroid hormone receptor superfamily by peroxisome proliferators, Nature 392 (1990) $512-516$

[45] Joshipura K.J., Asherio A., Manson J.E., Stampfer M.J., Rimm E.B., Speizer F.E., Hennekens C.H., Spiegelman D., Willett W.C., Fruit and vegetable intake in relation to risk of ischemic stroke, J. Am. Med. Assoc. 282 (1999) 1233-1239.

[46] Karamsetty M.R., Klinger J.R., Hill N.S., Phytoestrogens restore nitric oxide-mediated relaxation of isolated pulmonary arteries from chronically hypoxic rats, J. Pharm. Exp. Therap. 297 (2001) 968-974.

[47] Karin M., Delhase M., JNK or IKK, AP-1 or $\mathrm{NF}-\kappa \mathrm{B}$, which are the targets for MEK kinase 1 action? Proc. Natl. Acad. Sci. USA 95 (1998) 9067-9069.

[48] Kawada N., Seki S., Inoue M., Kuroki T., Effect of antioxidants, resveratrol, quercetin, an $\mathrm{N}$-acetylcysteine, on the functions of cultured rat hepatic stellate cells and Kupfer cells, Hepatology 27 (1998) 1265-1274.

[49] Keli S.O., Hertog E.J., Feskens E.J., Kromhout D., Dietary flavonoids, antioxidant vitamins, and incidence of stroke: the Zutphen study, Arch. Int. Med. 156 (1996) 637-642.

[50] Kiesewetter H., Koscielny J., Kalus U., Vix J.M., Peil H., Petrini O., van Toor B.S., de Mey C., Efficacy of orally administered extract of red wine leaf AS 195 (folia vitis viniferae) in chronic venous insufficiency (stages I-II). A randomised, double-blind, placebo-controlled trial, Arzneimittel-Forschung 50 (2000) 109-117.

[51] Kong A.N.T., Yu R., Lei W., Mandlekar S., Tan T.H., Ucker S., Differential activation of MAPK and ICE/Ced3 protease in chemical-induced apoptosis, Restor. Neurol. Neurosci. 12 (1998) 63-70. 
[52] Kong A.N.T., Mandlekar S., Yu R., Lei W. Fasanmande A., Pharmacodynamics and toxicodynamics of drug action: signalling in cell survival and cell death, Pharmaceut. Res. 16 (1999) 790-798.

[53] Kritchevsky D., Phytosterols, in: Kritchevsky D., Bonfield C. (Eds.), Dietary Fiber in Health and Disease, Plenum Press, New York, 1997, pp. 235-243.

[54] Kuroda Y., Shamsuddin A.M., Inositol phosphates have novel anticancer function, J. Nutr. 125 (1995) 725S-732S

[55] Lallena M.J., Diaz-Meco M.T., Bren G., Paya C.V., Moscat J., Activation of IkappaB kinase beta by protein kinase $\mathrm{C}$ isoforms, Mol. Cell. Biol. 19 (1999) 2180-2188.

[56] Laughton M.J., Evans P.J., Moroney M.A., Hoult J.R., Halliwell B., Inhibition of mammalian 5-lipooxygenase and cyclo-oxygenase by flavonoids and phenolic dietary additives Relationship to antioxidant activity and to iron ion-reducing ability, Biochem. Pharmacol. 42 (1991) 1673-1681.

[57] Lepley D.M., Pelling J.C., Induction of p21/ Waf1 and G(1) cell cycle arrest by the chemopreventive agent apigenin, Mol. Carcinogen. 19 (1997) 74-82

[58] Li D.P., Calzi S., Sanchez E.R., Inhibition of heat shock factor activity prevents heat shock potentiation of glucocorticoid receptor-mediated gene expression, Cell. Stress Chaperones 4 (1999) 223-234.

[59] Lin B., Williams-Skipp C., Tao Y., Schleicher M.S., Cano L., Duke R.C., Scheinman R.I. NF-KB functions as both a proapoptotic and antiapoptotic regulatory factor within a single cell type, Cell. Death Diff. 6 (1996) 570-582.

[60] Linder M., Falkner G., Srinivasan R., Hines R., Prough R., Role of canonical glucocorticoid response elements in modulating expression of genes regulated by the aryl hydrocarbon receptor, Drug. Metabol. Rev. 31 (1999) 247-271

[61] Lopez H.W., Remesy C., Demigne C., L'acide phytique : un composé utile? Med. Nutr. 4 (1998) 135-143.

[62] Mac Gregor J., Genetic and carcinogenic effects of plant flavonoids: an overview, in: Friedman M. (Ed.), Nutritional and toxicological aspects of food safety, Plenum Press, NY, 1984 pp. 497-526.

[63] Mattson M.P., Furukawa K., Anti-apoptotic actions of cycloheximide: blockade of programmed cell death or induction of programmed cell life? Apoptosis 2 (1997) 257-264.

[64] Mattson M.P., Goodman Y., Luo H., Fu W., Furukawa K., Activation of NF-kB protects hippocampal neurones against oxidative stressinduced apoptosis: evidence for induction of manganese superoxide dismutase and suppression of peroxynitrite production and protein tyrosine nitration, J. Neurosci. Res. 49 (1997) 681-697.
[65] Miksicek R.J., Estrogenic flavonoids: structural requirements for biological activity, Proc. Soc. Exp. Biol. Med. 208 (1995) 44-50.

[66] Milton K., Nutritional characteristics of wild primate foods: do the diets of our closest living relatives have lessons for us? Nutrition 15 (1999) 488-495.

[67] Mohan I.K., Das U.N., Prevention of chemically induced diabetes mellitus in experimental animals by polyunsaturated fatty acids, Nutrition 17 (2001) 126-151.

[68] Morton M.S., Chan P.S.F., Cheung C. Blacklock N., MatosFerreira A., Abranches Monteiro L., Correia R., Lloyd S., Griffiths K., Lignans and isoflavonoids in plasma and prostatic fluid in men: samples from Portugal, Hong Kong and the UK, Prostate 32 (1997) 122-128.

[69] Nakano H., Shindo M., Sakon S., Nishinaka S., Mihara M., Yagita H., Okumura K., Differential regulation of IkappaB kinase alpha and beta by two upstream kinases, NF-kappaB-inducing kinase and mitogen-activated protein kinase/ERK kinase kinase-1, Proc. Natl. Acad. Sci. USA 95 (1998) 3537-3542.

[70] Newton T., Patel N.M., Bhat-Nakshatri P., Stauss C.R., Goulet R.J., Nakshatri H., Negative regulation of transactivation function but not DNA binding of NF-kB and AP-1 by IкB $\beta 1$ in Breast Cancer Cells, J. Biol. Chem. 274 (1999) 18827-18835

[71] Nguyen T.T., The cholesterol-lowering action of plant stanol esters, J. Nutr. 129 (1999) 2109-2112.

[72] Ninomiya-Tsuji J., Kishimoto K., Hiyama A., Inoue J., Cao Z., Matsumoto K., The kinase TAK1 can activate the NIK-1 kappaB as well as the MAP kinase cascade in the IL-1 signalling pathway, Nature 398 (1999) 252-256.

[73] Ntambi J.M., Bene H., Polyunsaturated fatty acid regulation of gene expression, J. Mol. Neurosci. 16 (2001) 273-278.

[74] Ohta A., Ohtsuki M., Hosono A., Adachi T., Hara H., Sakata T., Dietary fructooligosaccharides prevent osteopenia after gastrectomy in rats, J. Nutr. 128 (1998) 106-110.

[75] Ooi V.E.C., Liu F., Immunomodulation and anti-cancer activity of polysaccharide-protein complexes, Curr. Med. Chemistry 7 (2000) 715-729.

[76] Ortuno A., Garcia-Puig D., Fuster M.D., Perez M.L., Sabater F., Porras I., Garcia-Lidon A., Del Rin J.A., Flavonone and flavone levels in different varietes of grapefruit and pumello, J. Agric. Food Chem. 43 (1995) 1-5.

[77] Orzechowski A., Grzelkowska K., Zimowska V., Skierski J., Płoszaj T., Bachanek K., Motyl T., Karlik W., Filipecki M., Induction of apoptosis and NF- $\mathrm{kB}$ by quercetin in growing murine L1210 lymphocytic leukaemic cells potentiated by TNF- $\alpha$, Repr. Nutr. Dev. 40 (2000) 441-465. 
[78] Peet G.W., Li J., IкB kinases $\alpha$ and $\beta$ show random sequential kinetic mechanism and are inhibited by staurosporine and quercetin, J. Biol. Chem. 247 (1999) 32655-32661.

[79] Persson H., Turk M., Nyman M., Sandberg A.S., Binding of $\mathrm{Cu} 2+, \mathrm{Zn} 2+$, and $\mathrm{Cd} 2+$ to inosito tri-, tetra-, penta-, and hexaphosphates, J. Agric. Food Chem. 48 (1998) 3194-3200.

[80] Petit P.X., Susin S.A., Zamzani N., Mignotte B., Kroemer G., Mitochondria and programmed cell death: back to the future, FEBS Lett. 396 (1996) 7-13.

[81] Peumans W.J., Van Damme E.J.M., Lectins as plant defence proteins, in: Pusztai A., Bardocz S (Eds.), Lectins - Biomedical Perspectives, Taylor \& Francis, 1995, pp. 1-22.

[82] Pinkus R., Weiner L.M., Daniel V., Role of oxidants and antioxidants in the induction of AP-1, $\mathrm{NF}-\kappa \mathrm{B}$, and glutathione S-transferase gene expression, J. Biol. Chem. 271 (1996) 13422-13429.

[83] Pusztai A., Grant G., Brown D.S., Bardocz S. Ewen S.W.B., Baintner K., Peumans W.J., Van Damme E.J.M., Lectins binding to the gut wall are growth factors for the pancreas: nutritional implications for transgenic plants, in: Pusztai A., Bardocz S. (Eds.), Lectins - Biomedical Perspectives, Taylor \& Francis, 1995, pp. 141-154.

[84] Renaud S., de Lorgeril M., Dalaye J., Guidollet J., Jacquard F., Mamelle N., Martin J.L., Manjaud I., Salen P., Toubol P., Creatan mediterranean diet for prevention of coronary heart disease, Am. J. Clin. Nutr. 61 (1995) 1360S-1367S.

[85] Richter M., Ebermann R., Marian B., Quercetininduced apoptosis in colorectal tumor cells possible role of EGF receptor signalling, Nutr. Cancer 34 (1999) 88-99.

[86] Rolfe B.G., Flavones and isoflavones as inducing substances of legume modulation, Biofactors 1 (1988) 3-10.

[87] Sato M., Miyazaki T., Kambe F., Maeda K. Seo H., Quercetin, a bioflavonoid, inhibits the induction of interleukin 8 and monocyte chemoattractant protein-1 expression by tumor necrosis factor- $\alpha$ in cultured human synovial cells, J. Rheumatol. 24 (1997) 1680-1684.

[88] Schouten G.J., Vertegaal A.C., Whiteside S.T. Israel A., Toebes M., Dorsman J.C., van der Eb A.J., Zantema A., IkappaB alpha is a target for the mitogen-activated $90 \mathrm{kDa}$ ribosomal S6 kinase, EMBO J. 16 (1997) 3133-3144.

[89] Serrano A., Palacios C., Roy G., Cespon C., Villar M., Nocito M., Gonzalez-Porque P., Derivatives of gallic acid induce apoptosis in tumoral cell lines and inhibit lymphocyte proliferation, Arch. Biochem. Biophys. 350 (1998) 49-54.

[90] Setchell K.D, Soy isoflavones-benefits and risks from nature's selective receptor modulators (SERMs), J. Am. Coll. Nutr. 20 (2001) 354S-362S.
[91] Srinivasula S.M., Ahmad M., Lin J.H., Poyet J.L., Fernandes-Alnemri T., Tsichlis P.N., Alnemri E.S., CLAP, a novel caspase recruitment domain - containing protein in the TNF receptor pathway, regulates $\mathrm{NF}-\kappa \mathrm{B}$ activation and apoptosis, J. Biol. Chem. 274 (1999) 17946-17954.

[92] Storlien L.H., Kraegen W.E., Chischolm D.J., Ford G.L., Bruce D.G., Pascoe W.E., Fish oil prevents insulin resistance induced by high fat feeding in rats, Science 237 (1987) 885-888.

[93] Sumitomo M., Tachibana M., Nakashima J., Murai M., Miyajima A., Kimura F., Hayakawa M., Nakamura H., An essential role for NF-кB in preventing TNF- $\alpha$ induced cell death in prostate cancer cells, J. Urol. 161 (1999) 674-679.

[94] Tanaka K., Hayatsu T., Negishi T., Hayatsu H., Inhibition of $\mathrm{N}$-nitrosation of secondary amines in vitro by tea extracts and catechins, Mutat. Res. 412 (1998) 91-98.

[95] Terao J., Piskuła M., Flavonoids and membrane lipid peroxidation inhibition. Editorial Comments/opinions, Nutrition 15 (1999) 790-791.

[96] Thompson M., Williams C.R., Stability of flavonoid complexes of copper(II) and flavonoid antioxidant activity, Anal. Chim. Acta 197 (1976) 375-355.

[97] Tournier C., Thomas G., Pierre J., Jacquemin C., Pierre M., Saunier B., Mediation by arachidonic acid metabolites of the $\mathrm{H} 2 \mathrm{O} 2$-induced stimulation of mitogen-activated protein kinases (extracellular-signal-regulated kinase and c-Jun NH2-terminal kinase), Eur. J. Biochem. 244 (1997) 587-595.

[98] Tsuda T., Kato Y., Osawa T., Mechanism for the peroxynitrite scavenging activity by anthocyanins, FEBS Lett. 484 (2000) 207-210.

[99] Urbano G., Lopez-Jurado M., Aranda P., VidalValverde C., Tenorio E., Porres J., The role of phytic acid in legumes: antinutrient or beneficial function? J. Physiol. Biochem. 56 (2000) 283-294.

[100] Van het Hof K.H., Boer H.S., Wiseman S.A. Lien N., Westrate J.A., Tijburg L.B., Consumption of green or black tea does not increase resistance of low-density lipoprotein to oxidation in humans, Am. J. Clin. Nutr. 66 (1998) 1125-1132.

[101] Van het Hof K.H., Kivitis G.A.A., Weststrate J.A., Tijburg L.B.M., Bioavailability of catechins from tea: the effect of milk, Eur. J. Clin. Invest. 52 (1998) 356-359.

[102] Wang C.Y., Cusack J.C., Liu R., Baldwin A.S., Control of inducible chemoresistance: enhanced antitumor therapy through increased apoptosis by inhibition of NF-кB, Nat. Med. 5 (1999) 412

[103] Wang Y., Wu T.R., Cai S., Welte T., Chin Y.E., Stat 1 as a component of Tumor Necrosis Factor alpha receptor 1-TRADD signaling complex to inhibit NF- $\mathrm{KB}$ activation, Mol. Cell. Biol. 20 (2000) 4505-4512. 
[104] Williams S.N., Shih H., Guenette D.K., Brackney W., Denison M.S., Pickwell G.V., Quattroch L.C., Comparative studies on the effects of green tea extracts and individual tea catechins on human CYP1A gene expression, Chem.-Biol. Interact. 128 (2000) 211-229.

[105] Xu J., Teran-Gracia M., Park J.H.Y., Nakamura M.T., Clarke S.D., Polyunsaturated fatty acids suppress hepatic sterol regulatory element binding protein-1 expression by accelerating transcript decay, J. Biol. Chem. 276 (2001) 9800-9807.

[106] Yamashita N., Tanemura H., Kawanishi S., Mechanism of oxidative DNA damage induced by quercetin in the presence of $\mathrm{Cu}$ (II), Mutat. Res. 425 (1999) 107-115.

[107] Young J.F., Nielsen S.E., Haraldsdottir J., Daneshvar B., Laurindsen S.T., Knuthsen P., Crozier A., Sandstrom B., Dragsted L.O., Effect of fruit juice intake on urinary quercetin excretion and biomarkers of antioxidative status, Am J. Clin. Nutr. 69 (1999) 87-94.

[108] Yu R., Jiao J.J., Duh J.L., Gudehithlu K., Tan T.H., Kong A.N.T., Activation of mitogen-activated kinases by green tea polyphenols: potential signaling pathways in the regulation of antioxidant-responsive element-mediated Phase II enzyme gene expression, Carcinogenesis 18 (1997) 451-456.

[109] Zamzani N., Hirsch T., Dallaporta B., Petit P.X. Kroemer G., Mitochondrial implication in accidental and programmed cell death: apoptosis and necrosis, J. Bioenerg. Biomembr. 29 (1997) 185-193.

[110] Zhang K., Wong K.P., Inhibition of the efflux of glutathione S-conjugates by plant polyphenols, Biochem. Pharmacol. 52 (1996) 1631-1638.

[111] Zhang K., Yang E.B., Tang W.Y., Wong K.P., Mack P., Inhibition of glutathione reductase by plant polyphenols, Biochem. Pharmacol. 54 (1997) 1047-1053.

[112] Zhao Q., Lee F.S., Mitogen-activated protein kinase/ERK kinase kinases 2 and 3 activate nuclear factor- $\kappa B$ through I $\kappa$ B kinase- $\alpha$ and IKB kinase- $\beta$, J. Biol. Chem. 274 (1999) $8355-8358$

[113] Zong W.X., Edelstein L.C., Chen C., Bash J., Gélinas C., The prosurvival Bcl-2 homolog $\mathrm{Bfl}-1 / \mathrm{A} 1$ is a direct transcriptional target of NF- $\kappa$ B that blocks TNF- $\alpha$ induced apoptosis, Genes Dev. 13 (1999) 382-387

\section{List of abbreviations}

AA - arachidonic acid; AhR - aryl hydrocarbon receptor; AP-1 - activator protein 1; ARE/ORE antioxidant/oxidant response element; Bcl-2/A1 - Bcl-2 antiapoptotic protein A1; BHA butylated hydroxyanisol; CAT - catalase; CYP - cytochrome p450; CYP1A1, CYP1A2 isoforms of cytochrome p450; DHA - docosahexaenoic acid; DHLA - dihomo-gamma-linolenic acid; DISC - death-initiated signaling complex; EGCG - epigallocatechin gallate; EPA eicosapentaenoic acid; ERK - extracellular signal-regulated kinase; FADD - Fas-associated death domain; FOS - fructo-oligosaccharides; GLA - gamma-linolenic acid; GPx - glutathione peroxidase; GR - glutathione reductase; GRE - glucocorticoid response element; GSH - reduced form of glutathione; GST - glutathione transferase; gstal, cyplal, cypla2 - genes for GST, CYP1A1, and CYP1A2, respectively; GTP - green tea polyphenols; ICE - interleukin 1 beta

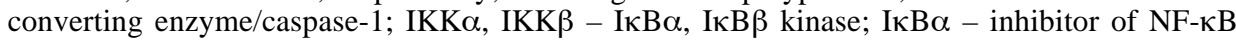
alpha; JNK - c-Jun N-terminal kinase; LA - linoleic acid; MAPKs - mitogen-activated protein kinases; MEKK1, MEKK2, MEKK3 - mitogen-activated protein kinase/ERK kinase 1, 2, 3; $\mathrm{NAD}(\mathrm{P}) \mathrm{H}$ - nicotinamide-adenine dinucleotide phosphate; NF- $\mathrm{KB}$ - nuclear factor kappa B; NIK nuclear factor kappa B inducing kinase; OFR - oxygen free radicals; PDGF/BB - platelet derived growth factor type BB; PI-3K - phosphatidylinositol 3-kinase; PKB - protein kinase B; PPAR peroxisome proliferator-activated receptor; PRE - PPAR response element; PSE - plant stanol esters; PUFA - polyunsaturated fatty acids; RIP - receptor interacting protein; ROS - reactive oxygen species; RXR $\alpha$ - 9-cis-retinoic acid receptor; SOD1- $\mathrm{Cu}$, Zn-dependent superoxide dismutase; SREBP - sterol regulatory element-binding protein; STAT1 - signal transducer and activator of transcription 1; TBARS - thiobarbituric acid reactive substances; tBHQ - $t$-butylhydroquinone; TCDD - 2,3,7,8-tetrachlorodibenzo-p-dioxin; TNF-R1, 2 -tumor necrosis factor alpha receptor 1, 2; TNF- $\alpha$ - tumor necrosis factor alpha; TRADD - TNF-R1-associated death domain; TRAF2- TNF-associated factor 2; UCP1, UCP3 - uncoupling protein 1, 3; UDP- uridine dinocleotide phosphate; XME - xenobiotic metabolising enzyme; XRE - xenobiotic response element. 